\section{Guide for Authors}

The American Journal of Alternative Agriculture publishes original research on biological, physical, or social science aspects of alternative and renewable agriculture and food systems. We particularly welcome multidisciplinary studies, but papers from a specific discipline also are invited. However, since AJAA readership is much broader than for a single-discipline journal, highly specialized terminology should be explained or avoided. The significance of a statement, or the reasoning behind a conclusion, may have to be spelled out more than in a more specialized journal. See http://www.cabi-publishing.org/journals/ajaa for an explanation of the various categories of articles.

Units. Research papers should use the International (SI, or metric) system throughout. Occasional use of common unit equivalents in parentheses is permitted.

Title Page. The title page should give the following information (all flush left): 1) title of the paper; 2) names of the authors; 3 ) affiliation and office address of authors, and 4) disclaimers, if any.

Abstract. The abstract should be 200 to 400 words, suitable for readers from a broad range of disciplines. It should avoid highly-specialized terminology that might be appropriate for a single-discipline journal. Take particular care that the significance of the work is made clear, even to readers from a different field.

Key Words. Provide subject matter key words suitable for use in scientific indexing.

Reference List. References should be listed in alphabetical order by author's name, and by year for a particular author (with letters after the year if needed). If a sole author is also the lead author of papers with multiple authors, use the following order: single author (by year); two authors (alphabetically by second author's name); three or more authors (by year). Repeat the author's name for each reference. Give the names of all authors in the reference, never use "et al."

Use full names of journals, institutions, conferences, etc. The reference list uses no quotation marks, italics, boldface or underlining. Only the names of books and periodicals are in initial capitals. Names of papers, book chapters, pamphlets, and bulletins are not capitalized.

Examples:

Arshad, M.A. and Coen, G.M., 1992. Characterization of soil quality: Physical and chemical criteria. American Journal of Alternative Agriculture 7:25-31.

Brink, R.H. Jr, Dubach, P., and Lynch, D.I., 1960. Measurement of carbohydrates in soil hydrolyzates with anthrone. Soil Science 89:157-166.

Coale, F.J. 1996. Descriptions of the soil test interpretive categories used by the University of Maryland Soil Testing Laboratory. SFM-3. University of Maryland, College Park.

Greenland, D.J., and Szabolcs, I., (eds). 1994. Soil Resilience and Sustainable Land Use. CAB International, Wallingford, UK.

Leopold, A. 1991. The farmer as a conservationist. In S. L. Flader and J. B. Callicott (eds). The River of the Mother of God and Other Essays by Aldo Leopold. University of Wisconsin Press, Madison, WI. p. 255-265.

Citing References. Cite references in the text by last name and year, with chapter or page numbers if the reference is a book or lengthy report. For two authors, give both names. Do not use "et al." unless there are three or more authors.
Footnotes. AJAA does not use bibliographic or substantive footnotes. All bibliographic references should be at the end of the text. Instead of substantive footnotes, include the material in the main text or consider eliminating it.

Manuscript Preparation. The entire manuscript, including abstract and references, should be typed on one side of standard-size paper, double spaced, with margins of at least one inch all around. Starting with the title page, label all pages in the upper right-hand corner with the lead author's last name and the page number. Do not use hyphens unless the hyphen is part of the word.

Indicate on the title page who the corresponding author is, and supply a present postal address, fax number and email address. The email address is particulariy important because page proofs will be sent electronically as a PDF file to the corresponding author for checking (see 'page proofs' section below for more detail). Tables should fit on one page, be numbered consecutively with Arabic numerals, and be on a separate sheet. Every figure and table should be mentioned at least once in the text. A detailed guide to formatting is available from the editorial office (address below).

Submission of manuscripts. Submit two high-quality copies (including any artwork), plus preferably a Microsoft Word disc version, to:

American Journal of Alternative Agriculture

clo Emma Durman

CABI Publishing

Nosworthy Way

Wallingford, Oxon OX10 8DE

UK

Email: ajaa@cabi.org

The cover letter should state that the manuscript is an original contribution that has not been published elsewhere in substantially the same form, that it is not currently under consideration elsewhere, and that permission has been obtained for any copyrighted material used.

Copyright. Papers are accepted on the understanding that the work has been submitted exclusively to the Journal. Authors will be supplied with a copyright form which must be completed and returned to the publisher. Papers will not be published until the signed copyright disclaimer has been received.

Page Proofs. Once typeset, the corresponding author will receive page proofs by email as a PDF file. You will be asked to print the PDF proof and mark any corrections to the printout before mailing back to $\mathrm{CABI}$ Publishing, or alternatively, detailing your corrections in an email to the Production Editor.

Offprints. Along with your PDF proof, you will also be emailed an offprint order form. If you wish to order offprints of your paper, complete this form using the price scale provided and return it with your corrected proof to CABI Publishing. However, if you do not wish to go to the expense of purchasing paper offprints, please be aware you will be provided with a final PDF flte by email at no expense.

\section{A Final Note}

Articles will be considered for publication in the AJAA only when submitted formally, in their final form, and formatted to the style of the AJAA. 


\section{AMERICAW JOURHAL OF ALTBRHATIVE AGRICULTRE}

Production and processing of organically grown fiber nettle (Urtica dioica L.) and its potential use in the natural textile industry: $A$ review C.R. Vogl and A. Hartl

In-row residue management effects on seed-zone temperature, moisture and early growth of barley and canola in a cold semi-arid region in northwestern Canada

M. (Charlie) A. Arshad and Rahman H. Azooz

Improving the nutrient status of a commercial dairy farm: An integrated approach

Derek H. Lynch, Rupert W. Jannasch, Alan H. Fredeen and Ralph C. Martin

The performance of organic and conventional cropping systems in an extreme climate year

D. W. Lotter, R. Seidel and W. Liebhardt

Growing out of the niche - can organic agriculture keep its promises? A study of two Austrian cases

Rebecka Milestad and Sonja Hadatsch

Agronomic performance and quality of spring wheat and soybean cultivars under organic culture

H.G. Nass, J.A. Ivany and J.A. MacLeod

Commentary

USDA research on organic farming: Better late than never

James F. Parr 